\title{
Investigation of the Biological Effects of Anti-Cell Adhesive Synthetic Peptides That Inhibit Experimental Metastasis of B16-F10 Murine Melanoma Cells
}

\author{
Martin J. Humphries, *\$ Kenneth M. Yamada, ${ }^{\ddagger}$ and Kenneth Olden** \\ ${ }^{*}$ Department of Oncology, Howard University Cancer Center, Washington, District of Columbia 20060; and ${ }^{\ddagger}$ Membrane Biochemistry \\ Section, Laboratory of Molecular Biology, National Cancer Institute, National Institutes of Health, Bethesda, Maryland 20892
}

\begin{abstract}
The experimental metastasis of B16-F10 murine melanoma cells is blocked by the anti-cell adhesive pentapeptide GlyArg-Gly-Asp-Ser (GRGDS) derived from the central cellbinding domain of fibronectin. In this report, we show that peptide treatment substantially extends the survival time for mice injected intravenously with B16-F10 cells $(8 / 8$ vs. $0 / 8$ mice alive at $150 \mathrm{~d}$ ), thereby demonstrating the potential efficacy of GRGDS treatment in protection against metastatic colonization. We have also examined the specificity of GRGDS activity by testing a series of related homologues for their effects on experimental metastasis. The overall profile of the relative inhibitory activities of these peptides closely matched their previously established capacity to disrupt adhesion in vitro. Lung retention studies with radiolabeled B16-F10 cells revealed an accelerated rate of cell loss from the lung 0-6 $h$ after coinjection with the active peptide GRGDS. This early effect of GRGDS was consistent with its short circulatory half-life, which was found to be $8 \mathrm{~min}$. Taken together, these results suggest that peptide-mediated inhibition of pulmonary colonization is due to interference with B16-F10 cell adhesion to structures in the target organ. Possible peptide interference in tumor cell-blood cell interactions was examined in order to assess (a) possible biological side-effects of peptide treatment and $(b)$ whether such interactions might be an alternative mechanism for GRGDS-mediated inhibition of pulmonary colonization. GRGDS was found to retain full inhibitory activity when coinjected with B16-F10 cells into mice in which platelet function was impaired by acetylsalicylic acid treatment or into thrombocytopenic mice treated with antiplatelet serum (76-93\% inhibition of colony formation). These data suggest that platelet involvement in the effects of the peptide is minimal. Similarly, GRGDS was also found to be a potent inhibitor of experimental metastasis in natural killer (NK) cell-deficient beige mice ( $86 \%$ inhibition), thereby discounting the possibility that GRGDS artifactually enhanced NK cell activity. We conclude as a result of these studies that cell-binding fibronectin peptides are specific inhibitors of experimental metastasis that prolong survival, that they appear to function by blocking the adhesion of B16-F10 cells to structures in the target organ, and that they do not appear to act through side effects on certain metastasis-related blood cell functions. In the future, deriva-
\end{abstract}

Address reprint requests to: Dr. Humphries, Howard University Cancer Center, 2041 Georgia Avenue N.W., Washington, D.C. 20060. Received for publication 12 March 1987 and in revised form 5 October 1987.

J. Clin. Invest.

(c) The American Society for Clinical Investigation, Inc 0021-9738/88/03/0782/09 \$2.00

Volume 81, March 1988, 782-790 tives of fibronectin peptides may be potentially useful prophylactic agents for interfering with the process of metastasis.

\section{Introduction}

The adhesive interaction of metastatic tumor cells with components of the extracellular matrix appears to be obligatory for successful target organ colonization (1-3). It is clear that attachment to, and penetration of, basement membrane and connective tissue structures takes place at multiple stages of the metastatic cascade. Recent studies have implicated the basement membrane glycoprotein laminin in metastatic colonization. Either preincubation $(3,4)$ or coculture $(5)$ of murine melanoma cells with the intact laminin molecule was found to enhance metastasis, while proteolytic cell-binding fragments have the opposite effect $(3,4)$.

Peptides containing the sequence Arg-Gly-Asp-Ser (RGDS), originally identified in the cell-binding domain of fibronectin, have been shown to be competitive, reversible inhibitors of cellular adhesion to extracellular matrix components (6-8). A relatively strict requirement for the particular sequence of amino acids in these peptides has been established as a result of extensive analysis in vitro $(6,7,9,10)$. We have recently reported that Gly-Arg-Gly-Asp-Ser (GRGDS) inhibits experimental metastasis when coinjected intravenously into syngeneic mice with lung-colonizing B16-F10 murine melanoma cells (11). Some of the specificity of peptide inhibition of adhesion that had been observed previously in vitro was also found in experimental metastasis assays, since two control peptides containing minor sequence alterations by amino acid inversion or conservative substitution were inactive (11). This result suggested that GRGDS might function by interfering with B16-F10 cell adhesion to target organ structures. In pulmonary retention studies using radiolabeled tumor cells, GRGDS was found to promote cell loss shortly after injection (11), a result consistent with early interference in tumor cellextracellular matrix interactions as the mechanism of action of the peptide. However, since the process of tumor metastasis is so complex $(12,13)$, it is conceivable that GRGDS may block at multiple sites. Recent evidence suggests that certain blood cell populations, particularly platelets and natural killer (NK) ${ }^{1}$ cells, play pivotal roles in regulation of tumor metastasis (reviewed in references 14-17), and it is possible that GRGDS may inhibit experimental metastasis by interfering with the normal functioning of these cells.

Many different types of tumor cells are known to elicit aggregation of platelets in vitro (18-21) and to cause thrombocytopenia when injected into experimental animals $(18,22)$. Both of these properties have been correlated with the meta-

1. Abbreviations used in this paper: APS, antiplatelet serum; NK, natural killer (cell). 
static potential of the tumor cells. Morphologic analysis of the process of experimental organ colonization has demonstrated that blood platelets bind in a time-dependent manner to capillary-arrested tumor cells over the first $4 \mathrm{~h}$ postinjection (23, 24). This interaction may stabilize the initial adhesion of tumor cells to the endothelial layer by increasing the size of tumor cell emboli as well as by shielding the tumor cells from immune detection. The results of preliminary trials employing antiplatelet drugs for prevention of metastasis have been equivocal partly because of the side effects of the drugs on normal vascular function (reviewed in references 14, 15, and 25). Nevertheless, in all cases examined to date, drug-induced thrombocytopenia has proven an effective inhibitor of experimental metastasis, therefore providing solid evidence for the role of platelets in the metastatic process (26-29).

NK cells are a subpopulation of lymphoid cells that appear to have an important role in the destruction of circulating tumor cell emboli (reviewed in references 16 and 17). Studies with animals exhibiting low levels of NK activity, including cyclophosphamide- or $\beta$-estradiol-treated mice, 3 -wk-old mice (30-34), and beige mice (34-37), have demonstrated an increased frequency of experimental and spontaneous metastasis. Similarly, activation of NK cell activity in vivo by administration of biological response modifiers renders the host more resistant to metastatic colonization $(38,39)$. Since NK cells can recognize and eliminate a wide variety of tumor cells without prior sensitization, it is likely that they are able to lyse targets shortly after their release into the vascular system.

As an initial step towards assessing potential prophylactic applications of GRGDS-like peptides and in order to gain insight into the mechanism of peptide action, we have tested the effect of GRGDS on survival of mice injected with B16-F10 cells. Furthermore, we have examined the specificity of peptide inhibition together with the contribution of tumor cellblood cell interactions to GRGDS-mediated inhibition of B16-F10 experimental metastasis.

\section{Methods}

Materials. Synthetic peptides, synthesized by Peninsula Laboratories (Belmont, CA), were further purified by Sephadex G10 chromatography in $10 \mathrm{mM} \mathrm{NH}_{4} \mathrm{HCO}_{3}$ as described (11). Peptides were $>98 \%$ pure by reversed-phase HPLC. $\left[{ }^{35} \mathrm{~S}\right]$ sodium sulfate $(25-40 \mathrm{Ci} / \mathrm{mg})$ was obtained from Amersham Corp. (Arlington Heights, IL). Acetylsalicylic acid was from Sigma Chemical Co. (St. Louis, MO).

Cell culture and experimental metastasis assay. B16-F10 murine melanoma cells, a line selected in vivo for high pulmonary colonization (40), were cultured as described $(41,42)$. Cultures were routinely tested for microbial infection and were verified to be mycoplasma-free. Cells were detached for 2 min with $0.02 \%$ EDTA and resuspended carefully to $5.0-7.5 \times 10^{5} / \mathrm{ml}$ in Dulbecco's modified Eagle's minimal essential medium (DME; Gibco, Grand Island, NY). Synthetic peptides, dissolved in divalent cation-free Dulbecco's phosphate-buffered saline ( PBS $^{-}$; Gibco), were neutralized and sterilized by microfiltration and mixed with cells. $0.2-\mathrm{ml}$ aliquots containing the specified amount of peptide together with $5.0-7.5 \times 10^{4}$ cells were injected slowly into the lateral tail vein of groups of eight C57BL/6 or C57BL/ $6^{\mathrm{bg} / \mathrm{bg}}$ mice (Charles River Breeding Laboratories, Wilmington, MA or Jackson Labs., Bar Harbor, ME, respectively) as described $(11,43)$. The animals were killed $14 \mathrm{~d}$ later with ether, their lungs were excised and fixed in $10 \%$ formaldehyde, and surface melanoma colonies were counted.

Pulmonary retention of radiolabeled B16-F10 cells. B16-F10 cells were plated at $2 \times 10^{6} / 75-\mathrm{cm}^{2}$ flask and the next day were labeled with $5-\left[{ }^{125} \mathrm{I}\right]$ iododeoxyuridine $(0.4 \mu \mathrm{Ci} / \mathrm{ml}, 200 \mathrm{mCi} / \mathrm{mmol}$; New England
Nuclear, Boston, MA) for $18 \mathrm{~h}$ in growth medium (44). Cells were then detached with EDTA as above, and aliquots were injected with or without GRGDS into the lateral tail vein of C57BL/6 mice. At different times, groups of three mice were killed by cervical dislocation, their lungs were excised, and then the radiolabel present in the DNA of dead cells was removed by extensive washing with $70 \%$ ethanol. Pulmonary radioactivity was then determined with a gamma counter (44).

Preparation of antiplatelet serum. Rabbit anti-mouse platelet serum (APS) was prepared exactly as described previously (27). Mouse platelets were prepared by differential centrifugation of whole mouse blood (Pel-Freez, Rogers, AR). 30-ml of blood was centrifuged in polypropylene tubes at $225 \mathrm{~g}$ for $10 \mathrm{~min}$ at room temperature, and the supernatant solution was resedimented to remove red blood cells. The resulting platelet-rich plasma was centrifuged at $1,400 \mathrm{~g}$ for $15 \mathrm{~min}$ at room temperature to sediment platelets. The pellet was washed and resuspended to a density of $2 \times 10^{8}$ cells $/ \mathrm{ml}$ with $0.9 \% \mathrm{NaCl}$, and was stored on ice prior to intravenous injection of $10^{9}$ platelets into adult New Zealand white rabbits. Platelets were counted as follows: $5 \mu$ l of platelet-rich plasma was mixed with $45 \mu 1$ of cerebrospinal fluid diluting fluid $(0.2 \%$ crystal violet in $10 \%$ glacial acetic acid; AJP Scientific, Clifton, NJ) and incubated at room temperature for $10 \mathrm{~min}$ to lyse red blood cells. The solution was then diluted appropriately ( $\sim 10$-fold), and the platelets were counted by hemocytometer. A boost injection of platelets prepared in the same way was administered after $20 \mathrm{~d}$, and the animals were exsanguinated $14 \mathrm{~d}$ later. Antisera were absorbed sequentially for $1 \mathrm{~h}$ at room temperature with mouse plasma proteinSepharose affinity gel and packed mouse red blood cells before decomplementation at $56^{\circ} \mathrm{C}$ for $30 \mathrm{~min}$.

Tritium labeling of synthetic peptides. Peptides were labeled with $\left[{ }^{3} \mathrm{H}\right]$ sodium borohydride by reductive methylation as described by Tack et al. (45). $12 \mathrm{mg}$ of peptide was dissolved in $250 \mu \mathrm{PBS}^{-}$, adjusted to $\mathrm{pH} 9$ and transferred to a glass Reacti-vial (Kontes Glass,

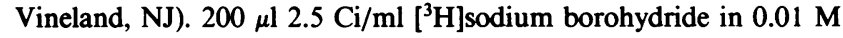
$\mathrm{NaOH}(74 \mathrm{Ci} / \mathrm{mmol}$; New England Nuclear) and $180 \mu \mathrm{l} 0.4 \mathrm{M}$ formaldehyde were added, and the solution was incubated at room temperature for $10 \mathrm{~min}$. Unreacted $\left[{ }^{3} \mathrm{H}\right]$ sodium borohydride was removed by Sephadex $\mathrm{G} 10$ chromatography in $10 \mathrm{mM} \mathrm{NH}_{4} \mathrm{HCO}_{3}$, and the void volume peak containing ${ }^{3} \mathrm{H}$-peptide was pooled and lyophilized. The labeled peptides were further purified by chromatography in $10 \mathrm{mM}$ $\mathrm{NH}_{4} \mathrm{HCO}_{3}$ on a $1.6 \times 90 \mathrm{~cm}$ Fractogel TSK HW-40(S) column (Pierce Chemical Co., Rockford, IL) and lyophilized.

Clearance of peptides from the circulation. C57BL/6 mice were injected as described above with $0.2-\mathrm{ml}$ aliquots of $\mathrm{PBS}^{-}$containing either $6 \mu \mathrm{mol}{ }^{3} \mathrm{H}$-peptides $(1 \mu \mathrm{Ci} / \mathrm{ml})$ or $\left[{ }^{35} \mathrm{~S}\right]$ sodium sulfate $(10 \mu \mathrm{Ci} /$ $\mathrm{ml})$. After various times, 5- $\mu \mathrm{l}$ samples of blood, withdrawn by cardiac puncture from groups of three mice, were added to $20 \mu \mathrm{l}$ of $3 \%$ sodium citrate in glass scintillation vials. $0.2 \mathrm{ml}$ of solubilizer consisting of Protosol (New England Nuclear):ethanol (1:2 [vol/vol]) was added, and the vials were incubated at $54^{\circ} \mathrm{C}$ for $2 \mathrm{~h}$. After cooling, $0.12 \mathrm{ml}$ $30 \%$ hydrogen peroxide was added slowly, and the vials were incubated a further $30 \mathrm{~min}$ at $54^{\circ} \mathrm{C}$. After cooling, $6 \mathrm{ml}$ of Biofluor (New England Nuclear) and $0.2 \mathrm{ml}$ of $0.5 \mathrm{M} \mathrm{HCl}$ were added before scintillation counting.

\section{Results}

Effect of GRGDS treatment on survival of mice. In an earlier study (11), we reported that a single injection of $3 \mathrm{mg}$ of the pentapeptide GRGDS along with B16-F10 murine melanoma cells was sufficient to reduce the pulmonary colonization potential of these cells by $>90 \%$. The inhibition was specific, nontoxic, and did not result from an impairment of cellular tumorigenicity. Furthermore, a 12-mo follow-up of the consequences of peptide administration in the absence of tumor cells on the growth rate of mice revealed no adverse effects. Therefore, in order to assess the possible protection afforded to 
C57BL/6 mice by GRGDS treatment, we examined the effect of a single coinjection of $3 \mathrm{mg}$ of peptide on the survival time of animals receiving i.v.-injected B16-F10 cells.

As shown in Fig. 1, all mice receiving $3 \times 10^{4} \mathrm{~B} 16-\mathrm{F} 10$ cells alone died between 32 and $46 \mathrm{~d}$ after injection (mean survival time of $35.8 \mathrm{~d}$ ). Autopsy revealed the presence of extensive melanotic lesions in the lungs. Mice receiving GRGDS, however, were all long-term survivors (still alive at $150 \mathrm{~d}$ postinjection; Fig. 1). Similar results were obtained after injection of 1 $\times 10^{4} \mathrm{~B} 16-\mathrm{F} 10$ cells $(0 / 8$ survivors if untreated and $8 / 8$ peptide-treated mice alive after $150 \mathrm{~d}$ postinjection; data not shown). This finding suggests that, in combination with normal host defenses, peptide treatment of the mice completely prevented the establishment of metastatic colonies and thereby essentially cured the animals. When this experiment was repeated with a larger inoculum of melanoma cells that would not be expected to completely inhibit colonization $\left(5 \times 10^{4}\right.$ cells; see reference 11 for a discussion of the dependence of GRGDS inhibition on inoculum size), no significant difference in survival time was observed (mean survival of $28.9 \pm 1.1$ and $27.3 \pm 1.9$ days for control and peptide-treated animals, respectively). Since the prognosis for mice bearing even a small number of melanotic colonies is very poor, it is likely that complete inhibition of colonization is required to observe prolongation of survival. From the results in Fig. 1, it is clear that by choosing an appropriate inoculum size, GRGDS can completely inhibit establishment of metastases, and that this inhibition translates into prolonged survival. We conclude as a result of these experiments that if an appropriate means of administration of GRGDS can be found, the peptide can prevent experimental metastatic disease such that host survival time is greatly enhanced.

Specificity of peptide inhibition of experimental metastasis. In order to examine in detail the specificity of inhibition of B16-F10 experimental metastasis by fibronectin-derived synthetic peptides, we have tested a larger library of homologous tetra- and pentapeptide molecules. These peptides include two that are found in the primary structure of the central cell-interaction site of fibronectin (RGDS and GRGDS), a truncated version of the latter peptide that lacks the $\mathrm{COOH}$-terminal serine residue (GRGD), an inverted peptide with reversed sequence (SDGR), and a homologue of GRGDS that contains a conservative substitution of glutamic acid for aspartic acid (GRGES).

Consistent with our previous report (11), coinjection of 6 $\mu$ mol ( $3 \mathrm{mg}$ ) GRGDS with $5 \times 10^{4}$ B16-F10 cells resulted in highly significant inhibition of melanotic colony formation (90\% inhibition, $P=0.002$, Table I). Assuming an extracellu-

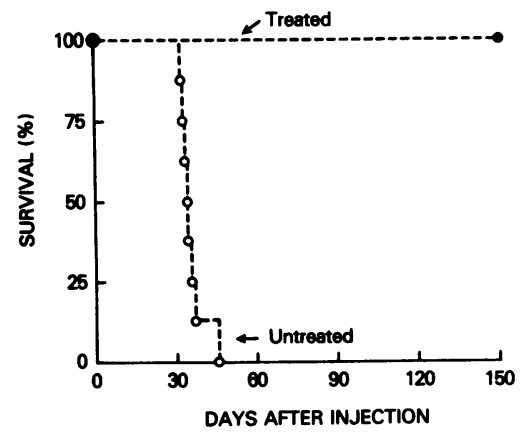

Figure 1. Effect of a single administration of 3 mg of GRGDS on survival of C57BL/6 mice injected with $3 \times 10^{4}$ B16-F10 cells. Melanoma cells and peptide were coinjected into the lateral tail vein and animal survival was then monitored as a function of time.
Table I. Effect of Different Fibronectin Peptide Homologues on B16-F10 Experimental Metastasis

\begin{tabular}{lcccc}
\hline Treatment & $\begin{array}{c}\text { Colony number } \\
\text { (mean } \pm \text { SE) }\end{array}$ & Inhibition & $\begin{array}{c}\text { Colony number, } \\
\text { median (and range) }\end{array}$ & $P$ \\
\hline & & $\%$ & & \\
Control & $83.2 \pm 30.1$ & - & $65(23-164)$ & - \\
GRGDS & $8.5 \pm 5.5$ & 90 & $2(0-44)$ & 0.002 \\
RGDS & $17.3 \pm 2.6$ & 79 & $18(8-25)$ & 0.01 \\
GRGES & $82.0 \pm 24.6$ & 1 & $71(26-174)$ & NS \\
GRGD & $59.2 \pm 12.8$ & 29 & $41(37-100)$ & NS \\
SDGR & $33.0 \pm 7.3$ & 60 & $36(12-53)$ & 0.05 \\
\hline
\end{tabular}

Each peptide ( $6 \mu \mathrm{mol})$ was coinjected with $5 \times 10^{4}$ B16-F10 cells into C57BL/6 mice as described in Methods. Melanotic colony formation was determined $14 \mathrm{~d}$ later. Statistical significance was estimated using the Mann-Whitney $U$ test.

lar fluid volume in the mouse of $6 \mathrm{ml}$, the initial concentration of GRGDS would be $1 \mathrm{mM}$. Since the affinities of fibronectin and GRGDS for the fibronectin receptor have previously been determined by direct binding studies to be 0.8 and $100 \mu \mathrm{M}$, respectively (46), injection of $6 \mu \mathrm{mol}$ peptide is reasonable for achieving competitive inhibition of a fibronectin-related adhesive event. GRGES displayed little or no activity (Table 1), demonstrating the extreme specificity of GRGDS inhibition. The shorter peptide, RGDS, was also highly active in blocking pulmonary colonization ( $79 \%$ inhibition at $6 \mu \mathrm{mol}, P=0.01$, Table I), although this degree of inhibition was less than that obtained with GRGDS. These results support a role for the RGDS tetrapeptide recognition signal in the colonization process, and rule out the possibility that GRGDS-mediated inhibition was an artifact of that particular pentapeptide amino acid sequence. At present, RGDS appears to be the minimal sequence that retains high inhibitory activity in cellular adhesion assays $(6,7,9,10)$. It is notable, however, that in studies in which RGDS and GRGDS have been compared directly for their ability to inhibit cell adhesion to fibronectin, the presence of the $\mathrm{NH}_{2}$-terminal glycine residue appeared to significantly increase the specific activity of the peptide $(6,10)$. Such findings in vitro are consistent with the in vivo results presented in Table I.

Peptides lacking the $\mathrm{COOH}$-terminal serine residue of the active RGDS tetrapeptide appear to have greatly reduced ability to disrupt cellular adhesion to extracellular matrix molecules in vitro, although a significant effect has been observed at concentrations $>500 \mu \mathrm{g} / \mathrm{ml}$ (10 and unpublished data). This result suggests that although the $\mathrm{COOH}$-terminal residue may not be absolutely required for peptide function, it does contribute quite significantly to peptide activity in vitro. Coinjection of $6 \mu \mathrm{mol}$ GRGD with B16-F10 cells resulted in 29\% inhibition of colony formation (Table I). Since the initial blood level of GRGD is likely to be $\sim 1 \mathrm{mg} / \mathrm{ml}$, assuming a blood volume of $\sim 2 \mathrm{ml}$, this low level of inhibition is consistent with the similarly minimal effects obtained in vitro.

Recently, it has been reported that the tetrapeptide SDGR, an inversion of the authentic RGDS sequence, also contains substantial inhibitory activity in cell adhesion assays (10). The reason for this somewhat surprising discovery is currently unknown, but it has coincidentally led to the identification of an 
apparent difference in the adhesive responses of two different cell types. Whereas RGDS and SDGR were almost equally active in blocking fibroblast spreading on immobilized fibronectin (10), the reverse peptide was without activity in assays measuring platelet binding and adhesion to fibronectin (47). From the data presented in Table I, it is clear that SDGR is also inhibitory in the experimental metastasis assay (60\% inhibition at $6 \mu \mathrm{mol}, P=0.05)$. Similar data have been obtained in a number of independent experiments at similar or higher significance levels. Combining the results of three experiments, the inhibition by SDGR was $54 \%$, a value significant at $P<0.001$. As discussed further below, this result provides indirect evidence against the involvement of platelets in peptide-mediated inhibition of colonization.

Circulatory retention of GRGDS. In our initial report (11), we performed one experiment to investigate the time frame over which GRGDS promoted cell loss from the lung. Using an assay designed to monitor retention of radiolabeled B16-F10 cells in the target organ, it was found that coinjection of GRGDS had two apparent effects on the kinetics of cell loss. First, there was a slight but reproducible drop in the number of cells that initially arrested in the lung, and second, over the initial postinjection period the number of arrested cells declined progressively until after $6 \mathrm{~h}$, fivefold fewer cells were present in the lungs of peptide-treated mice $(11$, and see also Fig. 3). To extend these findings, we have performed studies to examine the behavior of GRGDS in the circulation and to test whether the peptide is only active immediately after injection; i.e., is its principal mode of action to block the initial arrest of B16-F10 cells, or is it able to induce cell loss subsequent to tumor cell arrest?

One obviously important question concerns the actual half-life of GRGDS in the blood of mice. GRGDS was labeled with $\left[{ }^{3} \mathrm{H}\right]$ sodium borohydride by reductive methylation and injected into the lateral tail vein of C57BL/6 mice. At various times, blood samples were withdrawn by cardiac puncture and the level of radioactivity determined. The results shown in Fig. 2 demonstrate that the clearance of $\left[{ }^{3} \mathrm{H}\right] \mathrm{GRGDS}$ was both rapid and biphasic. A very rapid initial decrease in circulating peptide level (to $\sim 25 \%$ of the initial level) was detected from 0 to $2 \mathrm{~min}$ after injection, assuming a blood volume of $2 \mathrm{ml}$.

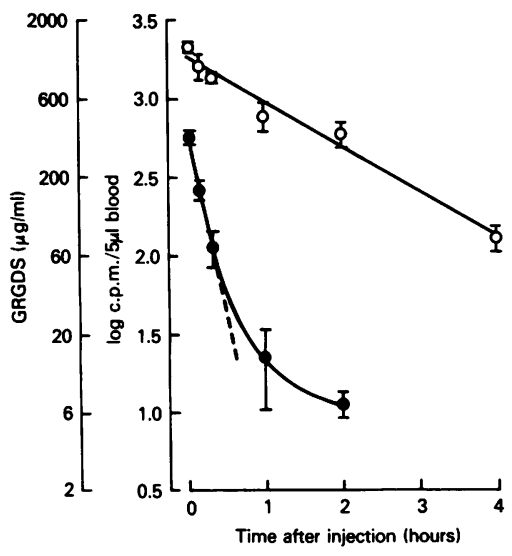

Figure 2. Clearance of $\left[{ }^{3} \mathrm{H}\right]$ GRGDS and $\left[{ }^{35} \mathrm{~S}\right]-$ sulfate from the vascular system of C57BL/6 mice. The level of radioactivity in blood samples was determined as described in Methods and used to calculate the estimated blood concentration of peptide. The first samples were withdrawn after 2 $\min$. The deviation from linearity of the GRGDS curve is due to the number of counts

approaching background. The half-life of each substance was calculated by regression analysis. Each point represents the mean of a group of three mice \pm SE. (0) Sulfate; (๑) GRGDS.
This initial decrease was probably due to rapid equilibration with interstitial fluid, since parallel injections of $\left[{ }^{35} \mathrm{~S}\right]$ sulfate exhibited a similar rapid decline (Fig. 2). The sulfate ion has been used to estimate interstitial fluid volume since it is distributed without obstruction into the extracellular space, yet its renal clearance occurs only at a relatively slow rate $(48,49)$. Control experiments demonstrated that GRGDS mock-labeled with sodium borohydride was equally effective as the unlabeled peptide in blocking cellular adhesion to fibronectin, thereby demonstrating that the labeling procedure did not affect the biological activity of GRGDS.

After initial equilibration ( $>2$ min postinjection), $\left[{ }^{3} \mathrm{H}\right]-$ GRGDS and $\left[{ }^{35}\right.$ S]sulfate were cleared at different rates (Fig. 2). The respective half-times were 8 and $63 \mathrm{~min}$. The clearance rate of GRGDS is therefore similar to that of other small protein molecules tested in previous studies $(50,51)$. The rapid clearance of GRGDS suggests that peptide-mediated inhibition of experimental metastasis occurs over the initial postinjection time period, since the concentration of peptide in plasma would be expected to fall to $<100 \mu \mathrm{g} / \mathrm{ml}$ within 30 min of injection. In order to exclude the possibility that the difference in antimetastatic activity of the peptide homologues employed in Table I might be inversely related to their half-life in the circulation, the clearance rate of $\left[{ }^{3} \mathrm{H}\right]-$ GRGES was determined. This was found to be $9 \mathrm{~min}$, a value very similar to that of GRGDS.

In view of the rapid clearance rate of GRGDS, we next investigated whether the effects of the peptide in vivo might be restricted to inhibition of tumor cell attachment rather than to dislodgement subsequent to arrest. It was conceivable that the decrease in the percentage of initially arrested cells induced by GRGDS (11) might be sufficient to trigger the rapid loss of remaining cells by host defense mechanisms. We have tested this hypothesis in the experiment shown in Fig. 3. Different numbers of $\left[{ }^{125}\right.$ I] iododeoxyuridine-labeled B16-F10 cells (3-5 $\times 10^{4}$ ) were injected in the absence of GRGDS, and the time course of pulmonary retention was followed for $6 \mathrm{~h}$. The rates of cell loss were compared with that of $5 \times 10^{4}$ cells coinjected with $6 \mu \mathrm{mol}$ GRGDS. We predicted that if the sole action of GRGDS was to reduce the number of initially attached cells, then the time course of cell loss in the presence of the peptide would follow that of an appropriate untreated inoculum designed to supply the same number of initially arrested cells. From the results in Fig. 3, however, GRGDS also appears to act subsequent to initial arrest, since cell inocula that yield fewer attached cells initially (3-4 × $10^{4}$ cells injected) were subsequently lost at a slower rate than peptide-treated cells that initially arrested at higher levels. We conclude, therefore, that despite its short circulatory half-life, GRGDS is able to promote B16-F10 cell dislodgement over the initial post-injection time period.

Tumor cell-blood cell interactions in GRGDS-mediated inhibition of experimental metastasis: role of platelets. Although the most likely mechanism of action of GRGDS in blocking experimental metastasis is direct interference with the adhesion of B16-F10 cells to extracellular matrix molecules in the blood vessel wall, the complexity of the metastatic process suggests that there are many other possible cell functions that, if blocked by peptide, could result in decreased colonization. The most obvious alternative site of action of GRGDS would be effects on blood cells. It is now well established that both platelets $(13,15)$ and NK cells $(16,17)$ play prominent roles in 


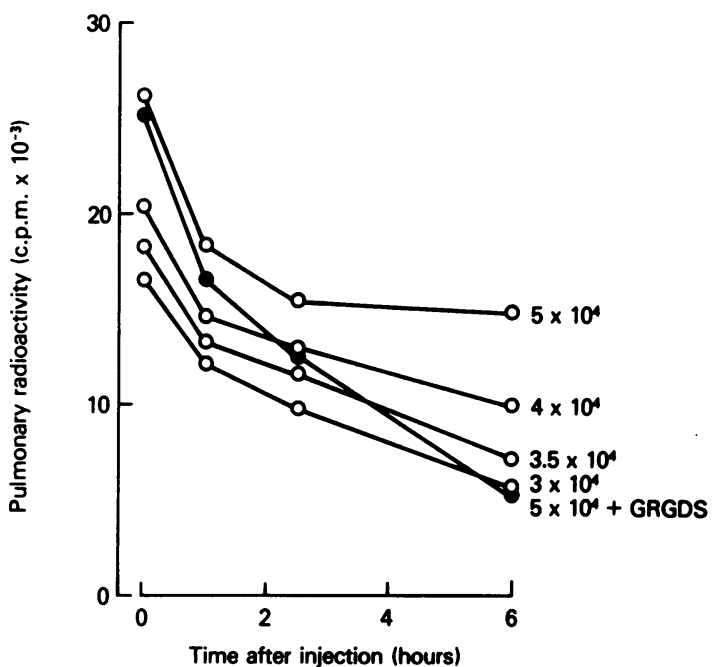

Figure 3. Effect of GRGDS on pulmonary retention of B16-F10 cells. Cultures were labeled with [ ${ }^{125}$ I]iododeoxyuridine and a range of initial cell numbers (indicated at the right) was injected into C57BL/ 6 mice with or without $6 \mu \mathrm{mol}$ GRGDS. At the indicated times after injection, pulmonary radioactivity was determined as described in Methods. Each point represents the mean of three mice. For the sake of clarity error bars are omitted, but in virtually every case experimental points differed from the mean by $\leq 10 \%$. (o) Control; (•) GRGDS.

the metastatic cascade, although with opposing effects. It is therefore possible that GRGDS could either inhibit platelet function or stimulate NK cell activity. These two systems are the most likely to be affected, since they both act soon after tumor cell release into the circulation. Platelets are thought to promote metastasis by binding to tumor cells in the blood and consequently facilitating lodgement in target organs. This process is postulated to occur shortly after tumor cell release. Alternatively, a potential artifactual stimulation of NK cell function by GRGDS is possible because NK activity requires no prior stimulation, unlike classical immune system function.

As mentioned above, our finding that the reverse peptide SDGR is active in blocking experimental metastasis of B16-F10 cells (Table I) suggests that platelets may not be the site of action of GRGDS, since SDGR is known to lack inhibitory activity in assays of platelet adhesion (47). However, since these assays could be quite different from situations encountered in vivo, we have carried out two experiments to test the effect of platelet-tumor cell aggregation on GRGDS-mediated inhibition of pulmonary colonization.

First, the circulating platelet count in mouse blood was decreased by injection of a specific antiplatelet serum (APS), and then the effect of GRGDS on B16-F10 colonization was examined. Injection of $0.05 \mathrm{ml}$ of APS reduced the platelet count by $55 \pm 19 \% 24 \mathrm{~h}$ later. Injection of an equal volume of preimmune serum produced no detectable reduction in platelet number. As anticipated from the results of Gasic et al. (27), the decrease in platelet count induced by APS resulted in a dramatic reduction in the ability of untreated B16-F10 cells to colonize the lungs of C57BL/6 mice $(73 \%$ inhibition, $P$ $=0.005$, Table II). In other experiments, this level of inhibition was found to be close to maximal. Injection of preimmune serum gave insignificant inhibition (9.3\%; Table II). This result confirms the key role that platelets play in promotion of experimental metastasis. When control mice, and mice preinjected $24 \mathrm{~h}$ earlier with $0.05 \mathrm{ml}$ APS or preimmune serum, were challenged with B16-F10 cells in the presence or absence of $6 \mu \mathrm{mol}$ GRGDS, the peptide was able to inhibit colonization in all animals to a similar degree $(76 \%, 77 \%$, and $79 \%$ inhibition in control, APS-treated and preimmune serum-treated animals, respectively; Table II). Mice treated with both APS and GRGDS exhibited 94\% inhibition of B16-F10 colonization relative to untreated animals (Table II), demonstrating an additivity of action. Since GRGDS is still fully active when the contribution of platelet adhesion is removed from the system, we conclude that its mechanism of action is to a large degree unrelated to inhibition of platelet function.

As a second test, mice were given acetylsalicylic acid in their drinking water for $3 \mathrm{~d}$ prior to challenge with B16-F10 cells in the presence or absence of GRGDS. It has been reported previously that administration of acetylsalicylic acid reduces platelet reactivity to collagen and also reduces experimental metastasis, although the extent of inhibition obtained was not as great as with APS $(18,27,29,52)$. Systemic administration of acetylsalicylic acid (3.5 $\mathrm{mM}$ in drinking water) to C57BL/6 mice reduced the level of B16-F10 cell pulmonary

Table II. Effect of APS on GRGDS-mediated Inhibition of B16-F10 Experimental Metastasis

\begin{tabular}{llcccc}
\hline Treatment of mice & Treatment of cells & $\begin{array}{c}\text { Colony number } \\
\text { (mean } \pm \text { SE) }\end{array}$ & Inhibition & $\begin{array}{c}\text { Colony number, } \\
\text { median (and range) }\end{array}$ \\
\hline & & & $\%$ & & $P$ \\
None & Control & $92.2 \pm 26.4$ & - & $73(33-187)$ & - \\
None & GRGDS & $22.1 \pm 5.5$ & 76 & $19(6-42)$ & 0.05 \\
$0.05 \mathrm{ml} \mathrm{PI}$ & Control & $83.6 \pm 13.4$ & 9 & $79(55-134)$ & NS \\
$0.05 \mathrm{ml} \mathrm{PI}$ & GRGDS & $17.8 \pm 3.6$ & 81 & $16(11-35)$ & 0.002 \\
$0.05 \mathrm{ml} \mathrm{APS}$ & Control & $25.3 \pm 5.8$ & 73 & $24(11-48)$ & 0.005 \\
$0.05 \mathrm{ml} \mathrm{APS}$ & GRGDS & $5.9 \pm 1.9$ & 94 & $9(0-10)$ & $<0.001$
\end{tabular}

$6 \times 10^{4}$ B16-F10 cells were coinjected with or without $6 \mu \mathrm{mol}$ GRGDS into groups of control C57BL/6 mice or mice preinjected $24 \mathrm{~h}$ earlier with $0.05 \mathrm{ml}$ preimmune (PI) rabbit serum or APS. Colony formation was determined after $14 \mathrm{~d}$. $P$ values were estimated by Mann-Whitney $U$ test. Each GRGDS-treated group was compared with its respective untreated control and the PI and APS controls were compared with the non-antibody-treated control. 
colonization by $28 \%(P=0.05$, Table III). This result is similar to that reported previously $(18,52)$. Coinjection of GRGDS with B16-F10 cells into acetylsalicylic acid-treated mice resulted in nearly equal inhibition of colonization as when tumor cells were injected into untreated mice $(90 \%$ and $93 \%$, respectively, $P<0.001$, Table III), thereby confirming the results obtained with APS and reinforcing the notion that platelets are not involved in GRGDS-mediated inhibition of experimental metastasis.

In addition to assays modulating platelet number or function by addition of exogenous agents, we also performed a control to test the possibility that GRGDS itself might affect the platelet count. However, $1 \mathrm{~h}$ after injection of either 6 $\mu \mathrm{mol}$ GRGDS or an equivalent volume of $\mathrm{PBS}^{-}$, there was no change in the number of platelets in C57BL/6 mouse blood $\left(3.02 \pm 0.73 \times 10^{9} / \mathrm{ml}\right.$ and $2.77 \pm 0.74 \times 10^{9} / \mathrm{ml}$, respectively, compared with $3.07 \pm 0.33 \times 10^{9} / \mathrm{ml}$ for uninjected mice).

Tumor cell-blood cell interactions in GRGDS-mediated inhibition of experimental metastasis: role of NK cells. As discussed above, the early effect of GRGDS on tumor cell dislodgement from the target organ implies that it is unlikely that any long-term stimulation of the immune system is involved in peptide-mediated inhibition of colonization. However, in order to rule out this possible mechanism, GRGDS was injected into mice $2 \mathrm{~d}$ prior to challenge with B16-F10 cells. From the data presented earlier in Fig. 2, it is clear that this preinjection time should be more than adequate to allow clearance of GRGDS from the circulation. If the peptide were acting via long-term immune stimulation, then the stimulus would have already been given to the mice and colonization could still have been inhibited. The number of colonies induced by $5 \times 10^{4} \mathrm{~B} 16-\mathrm{F} 10$ cells in control mice and in mice preinjected with $6 \mu \mathrm{mol}$ GRGDS were similar (29.6 \pm 5.2 and $33.5 \pm 3.6$, respectively), whereas mice in which GRGDS and B16-F10 cells were coinjected showed significant inhibition of colonization $(7.4 \pm 2.2$ colonies, $75 \%$ inhibition, $P<0.001)$.

If the immune system were to make a significant contribution to GRGDS-mediated inhibition of experimental metastasis, it would be more likely to involve components that do not require prior sensitization. In view of the proposed role of NK cells in reducing tumor metastasis, we have examined their role in peptide inhibition of B16-F10 experimental metastasis. In order to test directly the involvement of NK cells, we have employed C57BL/6 mice bearing the beige mutation. These mice are characterized by a specific genotypic defect in
NK activity $(35,36)$. If the sole action of GRGDS were to stimulate NK function, the peptide would be expected to be inactive in blocking colonization in beige mice. From the results presented in Table IV, it is clear that for the same number of B16-F10 cells injected, many more colonies were produced in beige mice. This result is consistent with previous reports $(37,53)$ and illustrates the role that NK cells play in removal of metastatic cells from the circulation. Interestingly, GRGDS was equally potent in blocking experimental metastasis of B16-F10 cells in both C57BL/6 and C57BL/6 $6^{\text {bg/bg }}$ mice $(86 \%$ and $81 \%$ inhibition, respectively, $P<0.001$ for both, Table IV), providing strong evidence that NK cells play an insignificant role in peptide-mediated inhibition. The small difference in percentage inhibition by GRGDS could be easily explained by inevitable inaccuracies in counting such large numbers of colonies per lung.

\section{Discussion}

In this study we have extended our previous work that established inhibition of B16-F10 experimental metastasis by GRGDS, a peptide derived from the cell adhesion site of fibronectin, and now report on the efficacy of peptide treatment for prevention of metastatic disease and its biological characterization after administration to mice. We conclude that GRGDS is able to prevent metastasis to such an extent that recipient mice survive substantially longer than mice not receiving peptide; that GRGDS inhibition is highly specific, is not restricted to effects on tumor cell attachment, but for the most part occurs over the initial postinjection period (0-6 h); and that no deleterious or stimulatory effects on blood cell function in metastasis (platelets, NK cells, other immune cells) were detected as a consequence of GRGDS administration.

By examining the survival time for animals receiving a single coinjection of B16-F10 cells and GRGDS, we have demonstrated that the peptide is effective at preventing formation of metastases such that not only is colony formation inhibited, but also that this inhibition translates into a substantial prolongation of life-span. $100 \%$ of mice receiving $3 \mathrm{mg}$ of GRGDS along with $1 \times 10^{4}$ or $3 \times 10^{4} \mathrm{~B} 16-\mathrm{F} 10$ cells were still alive $>150 \mathrm{~d}$ later and were therefore classified as long-term survivors. Although metastases are often present at the time of clinical presentation of the primary tumor, anti-cell adhesive peptides may be useful as an adjuvant to standard chemother-

Table III. Effect of Acetylsalicylic Acid on GRGDS-mediated Inhibition of B16-F10 Experimental Metastasis

\begin{tabular}{|c|c|c|c|c|c|}
\hline Treatment of mice & Treatment of cells & $\begin{array}{l}\text { Colony number } \\
\text { (mean } \pm \mathrm{SE})\end{array}$ & Inhibition & $\begin{array}{l}\text { Colony number, } \\
\text { median (and range) }\end{array}$ & $P$ \\
\hline & & & $\%$ & & \\
\hline None & Control & $224 \pm 27.2$ & - & $219(110-341)$ & - \\
\hline None & GRGDS & $15.4 \pm 2.3$ & 93 & $13(11-29)$ & $<0.001$ \\
\hline ASA & Control & $161 \pm 11.6$ & 28 & $151(120-209)$ & 0.05 \\
\hline ASA & GRGDS & $16.5 \pm 3.9$ & 90 & $13(7-40)$ & $<0.001$ \\
\hline
\end{tabular}

$7 \times 10^{4} \mathrm{~B} 16-\mathrm{F} 10$ cells were coinjected with or without $6 \mu \mathrm{mol}$ GRGDS into groups of control mice or mice given $3.5 \mathrm{mM}$ acetylsalicylic acid (ASA) in their drinking water for $3 \mathrm{~d}$ prior to injection. Colony formation was determined after $14 \mathrm{~d}$. $P$ values were estimated by Mann-Whitney U test. GRGDS-treated groups were compared with their respective untreated controls and the acetylsalicylic acid control was compared with the complete negative control. 
Table IV. Effect of GRGDS on B16-F10 Experimental Metastasis in Beige Mice

\begin{tabular}{llccc}
\hline \multicolumn{1}{c}{ Mice } & $\begin{array}{c}\text { Treatment } \\
\text { of cells }\end{array}$ & $\begin{array}{c}\text { Colony } \\
\text { number } \\
\text { (mean } \pm \text { SE) }\end{array}$ & $\begin{array}{c}\text { Relative } \\
\text { inhibition }\end{array}$ & $\begin{array}{c}\text { Colony number, } \\
\text { median } \\
\text { (and range) }\end{array}$ \\
\hline & & & $\%$ & \\
$\mathrm{C57BL} / 6$ & Control & $111 \pm 17.0$ & - & $118(47-192)$ \\
$\mathrm{C} 57 \mathrm{BL} / 6$ & GRGDS & $15.8 \pm 2.4$ & 86 & $15(8-28)$ \\
$\mathrm{C} 57 \mathrm{BL} / 6^{\mathrm{bg} / \mathrm{bg}}$ & Control & $\gg 300$ & - & $\gg 300$ \\
$\mathrm{C} 57 \mathrm{BL} / 6^{\mathrm{bg} / \mathrm{bg}}$ & GRGDS & $229 \pm 17.6$ & $24^{*}$ & $217(181-303)$
\end{tabular}

$7 \times 10^{4} \mathrm{~B} 16-\mathrm{F} 10$ cells were coinjected with or without $6 \mu \mathrm{mol}$ GRGDS into groups of C57BL/6 or C57BL/6 $6^{\mathrm{bg} / \mathrm{bg}}$ mice. Colony formation was determined $14 \mathrm{~d}$ later. Each GRGDS-treated group was compared to its respective untreated control.

* This value is an underestimate of the inhibition by GRGDS in beige mice, since many more than 300 colonies were present in the control. The raw data for the number of colonies formed in the absence of peptide in beige mice (line 3) was $1,210 \pm 53.7$. Using this figure, the relative inhibition by GRGDS in beige mice was calculated to be $81 \%$. However, since there are inevitable inaccuracies in counting this many colonies, the data in the table are presented according to the general convention used when there are too many colonies to count precisely.

apy or immunotherapy, or to prevent seeding of metastatic cells after surgical removal of a primary tumor.

From a comparison of the effects of a library of homologous synthetic peptides of similar size, we have established the specificity pattern of the phenomenon of GRGDS-mediated inhibition of pulmonary colonization. Among the peptides tested, both GRGDS and RGDS were highly inhibitory, and the reverse sequence of the latter peptide, SDGR, also possessed substantial activity. Two other homologues, GRGES, which contains a highly conservative substitution of a glutamic acid residue for an aspartic acid residue, and GRGD, which lacks the $\mathrm{COOH}$-terminal serine residue of GRGDS, possessed greatly reduced activity. As a whole, this profile of inhibition by the peptide library is very similar to their relative potencies in inhibitory assays measuring cellular adhesion in vitro $(6,7$, 9, 10). This close correlation provides strong evidence supporting the contention that the active peptides (GRGDS, RGDS, and SDGR) inhibit experimental metastasis by interfering with the adhesive function of B16-F10 cells. Thus these results demonstrate the involvement of the RGD-recognition signal in the tumor colonization process. At present we cannot be certain which GRGDS-sensitive extracellular matrix molecule is involved in colonization, since several potential candidates are known to contain RGD sequences (including fibronectin, serum spreading factor/vitronectin, fibrinogen, collagens, and von Willebrand factor [6,54-56]). Although the complete amino acid sequence of laminin has not yet been published, there is currently no evidence for an RGD-related determinant (Yamada, Y., personal communication). Furthermore, RGDS and GRGDS are only slightly inhibitory in assays measuring cell adhesion to laminin in vitro (57), suggesting that laminin is not the ligand whose function is blocked by these peptides in vivo. It appears, therefore, that metastatic tumor cells may use more than one adhesion factor during colonization, since it is now well established that interference in tumor cell-laminin binding can also prevent experimental metastasis (3-5).

In an attempt to discriminate between potential effects of GRGDS on tumor cell attachment and dislodgement, we designed an experiment to test whether the inhibition of colonization observed with GRGDS treatment could be explained solely by blockage of B16-F10 cell attachment to the lung. However, since the rate of loss of B16-F10 cells from the target organ was higher in peptide-treated mice than in control mice containing similar or lower numbers of initially arrested cells, it is apparent that GRGDS continues to promote tumor cell loss subsequent to their initial arrest in the capillary bed of the lung. This result, coupled with previously published lung retention data, plus the finding that the circulatory half-life of $\left[{ }^{3} \mathrm{H}\right]$ GRGDS is only $8 \mathrm{~min}$, is strong evidence that the decrease in melanotic colony formation observed $2 \mathrm{wk}$ after tumor cell injection is in large part due to peptide-promoted cell losses occurring during the first few hours postinjection. Again, this conclusion is consistent with our postulated mechanism of disruption of adhesion by the peptide, since it is likely that there is only a narrow window during which tumor cells will be sensitive to detachment. Once the cells penetrate the endothelium, traverse the underlying basement membrane, and lodge in extracellular spaces, it is unlikely that inhibitors of adhesion would be able to cause such detachment.

In addition to possible effects on adhesion, an early site of action of GRGDS could also theoretically include modulation of tumor cell-blood cell interactions. In particular, it is well established that tumor cell-platelet aggregation is a significant factor in determining the arrest and survival of circulating metastatic cells $(14,15)$. Since GRGDS has been reported to block platelet aggregation $(47,58)$, it was conceivable that the peptide might be acting at least partly via interference with the binding of platelets to injected B16-F10 cells. Shortly after injection, GRGDS did not alter the number of circulating platelets, suggesting that an artifactual effect on the platelet count could not account for the biological activity of the peptide. Furthermore, since GRGDS was equally active in blocking experimental metastasis in mice rendered thrombocytopenic with APS or treated with acetylsalicylic acid, it appears that any contribution of platelet aggregation to GRGDS-mediated inhibition of pulmonary colonization is minimal.

Removal of metastatic tumor cells by NK cells without prior sensitization is now thought to play a major role in natural host defense against tumors $(16,17)$. By employing C57BL/6 mice bearing the homozygous beige mutation, we have therefore examined the role of NK cell function as a contributor to the promotion of tumor cell dislodgement by GRGDS. Despite the 11-fold increase in melanotic colony formation observed in beige mice, GRGDS still possessed full activity in blocking experimental metastasis of B16-F10 cells, suggesting that GRGDS does not block colonization by stimulating NK activity. It is notable that the inhibitory capacity of the peptide is independent of the final number of colonies observed. Instead, its relative activity is only a function of the size of the tumor cell inoculum as reported previously (11).

In conclusion, we have performed studies to test the potential efficacy of fibronectin-derived peptides for prevention of experimental metastasis. The inhibitory activity is specific, and all of the data are consistent with a mechanism of action involving interference with tumor cell adhesion to the target organ. It should be noted, however, that we cannot presently 
entirely exclude the possibility that RGD-containing peptides may have unpredictable physiological effects that directly influence metastatic capacity (e.g., effects on tumor cell invasion through interference with extracellular proteolysis [1-3]). It is also clear as a result of these studies that, in order for GRGDS to be useful in preventing tumor metastasis, its circulatory concentration will need to be maintained at a high level either by continuous infusion or by artificially increasing its half-life by structural modification.

\section{Acknowledgments}

We thank Dr. I. J. Fidler (M. D. Anderson Hospital, University of Texas, Houston, TX) for providing B16-F10 cells, Dr. Steven K. Akiyama for his comments on the manuscript, and Danny Newhouse (National Cancer Institute, Frederick Cancer Research Facility, Frederick, MD) for injection of rabbits.

This work was supported in part by grants CA-14718 and CA-45290 from the National Institutes of Health and grant PDT-312 to Dr. Olden from the American Cancer Society.

Note added in proof. The animals treated with peptide in Fig. 1 were still alive 12 mo after injection.

\section{References}

1. Nicolson, G. L. 1982. Cancer metastasis: organ colonization and the cell-surface properties of malignant cells. Biochim. Biophys. Acta. 695:113-176.

2. Liotta, L. A., C. N. Rao, and S. H. Barsky. 1983. Tumor invasion and the extracellular matrix. Lab. Invest. 49:636-649.

3. McCarthy, J. B., M. L. Basara, S. L. Palm, D. F. Sas, and L. T. Furcht. 1985. The role of cell adhesion proteins-laminin and fibronectin-in the movement of malignant and metastatic cells. Cancer Metastasis Rev. 4:125-152.

4. Barsky, S. H., C. N. Rao, J. E. Williams, and L. A. Liotta. 1984. Laminin molecular domains which alter metastasis in a murine model. J. Clin. Invest. 74:843-848.

5. Terranova, V. P., J. E. Williams, L. A. Liotta, and G. R. Martin. 1984. Modulation of the metastatic activity of melanoma cells by laminin and fibronectin. Science (Wash. DC). 226:982-985.

6. Pierschbacher, M. D., and E. Ruoslahti. 1984. Cell attachment activity of fibronectin can be duplicated by small synthetic fragments of the molecule. Nature (Lond.). 309:30-33.

7. Yamada, K. M., and D. W. Kennedy. 1984. Dualistic nature of adhesion protein function: fibronectin and its biologically active peptide fragments can autoinhibit fibronectin function. J. Cell Biol. 99:29-36.

8. Silnutzer, J. E., and D. W. Barnes. 1985. Effects of fibronectin peptides on cell spreading. In Vitro (Rockville). 21:73-78.

9. Pierschbacher, M. D., and E. Ruoslahti. 1984. Variants of the cell recognition site of fibronectin that retain attachment-promoting activity. Proc. Natl. Acad. Sci. USA. 81:5985-5988.

10. Yamada, K. M., and D. W. Kennedy. 1985. Amino acid sequence specificities of an adhesive recognition signal. J. Cell. Biochem. 28:99-104.

11. Humphries, M. J., K. Olden, and K. M. Yamada. 1986. A synthetic peptide from fibronectin inhibits experimental metastasis of murine melanoma cells. Science (Wash. DC). 233:467-470.

12. Fidler, I. J., D. M. Gersten, and I. R. Hart. 1978. The biology of cancer invasion and metastasis. Adv. Cancer Res. 28:149-250.

13. Poste, G., and I. J. Fidler. 1980. The pathogenesis of cancer metastasis. Nature (Lond.). 283:139-146.

14. Mehta, P. 1984. Potential role of platelets in the pathogenesis of tumor metastasis. Blood. 63:55-63.

15. Gasic, G. J. 1984. Role of plasma, platelets, and endothelial cells in tumor metastasis. Cancer Metastasis Rev. 3:99-116.

16. Herberman, R. B. 1984. Possible role of natural killer cells and other effector cells in immune surveillance against cancer. J. Invest. Dermatol. 83(1S):137s-140s.

17. Hanna, N. 1985. The role of natural killer cells in control of tumor growth and metastasis. Biochim. Biophys. Acta. 780:213-226.

18. Gasic, G. J., T. B. Gasic, N. Galanti, T. Johnson, and S. Murphy. 1973. Platelet-tumor cell interactions in mice: the role of platelets in the spread of malignant disease. Int. J. Cancer. 11:704-718.

19. Pearlstein, E., L. B. Cooper, and S. Karpatkin. 1979. Extraction and characterization of a platelet-aggregating material from SV40transformed mouse 3T3 fibroblasts. J. Lab. Clin. Med. 93:332-344.

20. Pearlstein, E., P. L. Salk, G. Yogeeswaran, and S. Karpatkin. 1980. Correlation between spontaneous metastatic potential, plateletaggregating activity of cell surface extracts, and cell surface sialylation in 10 metastatic-variant derivatives of a rat renal sarcoma cell line. Proc. Natl. Acad. Sci. USA. 77:4336-4339.

21. Honn, K. V., P. Cavanaugh, C. Evens, C. D. Taylor, and B. F. Sloane. 1982. Tumor-cell platelet aggregation induced by cathepsin B-like protease and inhibited by prostacyclin. Science (Wash. DC). 217:540-542.

22. Hilgard, P., H. Heller, and C. G. Schmidt. 1976. The influence of platelet aggregation inhibitors on metastasis formation in mice (3LL). Z. Krebsforsch. 86:243-250.

23. Jones, D. S., A. C. Wallace, and E. F. Fraser. 1971. Sequence of events in experimental metastasis of Walker 256 tumor: light, immunofluorescent and electron microscopic observations. J. Natl. Cancer Inst. 46:493-504.

24. Sindelar, W. F., T. S. Tralka, and A. S. Ketcham. 1975. Electron microscopic observations on formation of pulmonary metastasis. J. Surg. Res. 18:137-161.

25. Al-Mondhiry, H. 1984. Tumor interaction with hemostasis: the rationale for the use of platelet inhibitors and anticoagulants in the treatment of cancer. Am. J. Hematol. 16:193-202.

26. Gasic, G., and T. Gasic. 1962. Removal of sialic acid from the cell coat in tumor cells and vascular endothelium and its effects on metastasis. Proc. Natl. Acad. Sci. USA. 48:1172-1177.

27. Gasic, G., T. Gasic, and C. C. Stewart. 1968. Anti-metastatic effects associated with platelet reduction. Proc. Natl. Acad. Sci. USA. 61:46-52.

28. Kolenich, J. J., E. G. Mansour, and A. Flynn. 1972. Haematological effects of aspirin. Lancet. 2:714.

29. Ivarsson, L. 1976. Metastasis formation after intravenous tumor cell injection in thrombocytopenic rats. Eur. Surg. Res. 8:51-60.

30. Hanna, N., and I. J. Fidler. 1980. Role of natural killer cells in the destruction of circulating tumor emboli. J. Natl. Cancer Inst. 65:801-809.

31. Mantovani, A., W. Luini, G. Peri, A. Vecchi, and F. Spreafico. 1978. Effect of chemotherapeutic agents on natural cell-mediated cytotoxicity in mice. J. Natl. Cancer Inst. 61:1255-1261.

32. Djeu, J. Y., J. A. Heinbaugh, W. D. Vieira, H. T. Holden, and R. B. Herberman. 1979. The effect of immunopharmacological agents on mouse natural cell-mediated cytotoxicity and on its augmentation by poly I.C. Immunopharmacology. 1:231-244.

33. Seaman, W. E., M. A. Blackman, T. D. Gindhart, J. R. Roubinia, J. M. Loeb, and N. Talal. 1978. $\beta$-Estradiol reduces natural killer cells in mice. J. Immunol. 121:2193-2198.

34. Hanna, N., and R. C. Burton. 1981. Definitive evidence that natural killer $(\mathrm{NK})$ cells inhibit experimental tumor metastasis in vivo. J. Immunol. 127:1754-1758.

35. Roder, J., and A. Duwe. 1979. The beige mutation in the mouse selectively impairs natural killer cell function. Nature (Lond.). 278:451-453.

36. Roder, J. C., M. L. Lohmann-Matthes, W. Domzig, and H. Wigzell. 1979. The beige mutation in the mouse. II. Selectivity of the natural killer (NK) cell defect. J. Immunol. 123:2174-2181.

37. Talmadge, J. E., K. M. Meyers, D. J. Prieur, and J. R. Starkey. 1980. Role of NK cells in tumor growth and metastasis in beige mice. Nature (Lond.). 284:622-624. 
38. Herberman, R. B., J. R. Ortaldo, and G. D. Bonnard. 1979. Augmentation by interferon of human natural and antibody-dependent cell-mediated cytotoxicity. Nature (Lond.). 277:221-223.

39. Senik, A., I. Gresser, C. Maury, M. Gidlund, A. Orn, and H. Wigzell. 1979. Enhancement by interferon of natural killer cell activity in mice. Cell. Immunol. 44:186-200.

40. Fidler, I. J. 1973. Selection of successive tumour lines for metastasis. Nat. New Biol. (Lond.). 242:148-149.

41. Fidler, I. J. 1974. Inhibition of pulmonary metastasis by intravenous injection of specifically activated macrophages. Cancer Res. 34:1074-1078.

42. Humphries, M. J., K. Matsumoto, S. L. White, and K. Olden. 1986. Oligosaccharide modification by swainsonine treatment inhibits pulmonary colonization by B16-F10 murine melanoma cells. Proc. Natl. Acad. Sci. USA. 83:1752-1756.

43. Fidler, I. J. 1978. General considerations for studies of experimental cancer metastasis. Methods Cancer Res. 15:399-439.

44. Fidler, I. J. 1970. Metastasis: quantitative analysis of distribution and fate of tumor emboli labeled with ${ }^{125}$ I-5-iodo-2'-deoxyuridine. J. Natl. Cancer Inst. 45:773-782.

45. Tack, B. F., J. Dean, D. Eilat, P. E. Lorenz, and A. N. Schechter. 1980. Tritium labeling of proteins to high specific radioactivity by reduction methylation. J. Biol. Chem. 255:8842-8847.

46. Akiyama, S. K., E. Hasegawa, T. Hasegawa, and K. M. Yamada. 1985. The interaction of fibronectin fragments with fibroblastic cells. J. Biol. Chem. 260:13256-13260.

47. Haverstick, D. M., J. F. Cowan, K. M. Yamada, and S. A. Santoro. 1985. Inhibition of platelet adhesion to fibronectin, fibrinogen and von Willebrand factor substrates by a synthetic tetrapeptide derived from the cell binding domain of fibronectin. Blood. 66:946956.

48. Walser, M., D. W. Seldin, and A. Grollman. 1953. An evaluation of radiosulfate for the determination of the volume of extracellular fluid in man and dogs. J. Clin. Invest. 32:299-311.
49. McGrath, B. P., D. J. Tiller, J. S. Horvath, and J. R. Johnson. 1976. Measurement of extracellular fluid in patients on maintenance hemodialysis. Kidney Int. 9:57-59.

50. Beauchamp, C. O., S. L. Gonias, D. P. Menapace, and S. V. Pizzo. 1983. A new procedure for the synthesis of polyethylene glycolprotein adducts: effects on function, receptor recognition, and clearance of superoxide dismutase, lactoferrin, and alpha ${ }_{2}$-macroglobulin. Anal. Biochem. 131:25-33.

51. Rajagopalan, S., S. L. Gonias, and S. V. Pizzo. 1985. A nonantigenic covalent streptokinase-polyethylene glycol complex with plasminogen activator function. J. Clin. Invest. 75:413-419.

52. Gasic, G. J., T. B. Gasic, and S. Murphy. 1972. Anti-metastatic effect of aspirin. Lancet. 2:932-933.

53. Hanna, N., and I. J. Fidler. 1981. Relationship between metastatic potential and resistance to natural killer cell-mediated cytotoxicity in three murine tumor systems. J. Natl. Cancer Inst. 66:1183-1190.

54. Suzuki, S., A. Oldberg, E. G. Hayman, M. D. Pierschbacher, and $\mathrm{E}$. Ruoslahti. 1985. Complete amino acid sequence of vitronectin deduced from cDNA. Similarity of cell attachment sites in vitronectin and fibronectin. EMBO (Eur. Mol. Biol. Organ.) J. 4:2519-2524.

55. Jenne, D., and K. K. Stanley. 1985. Molecular cloning of Sprotein, a link between complement, coagulation and cell-substrate adhesion. EMBO (Eur. Mol. Biol. Organ.) J. 4:3153-3157.

56. Sadler, J. E., B. B. Shelton-Inloes, J. M. Sorace, J. M. Harlan, K. Titani, and E. W. Davie. 1985. Cloning and characterization of two cDNAs coding for human von Willebrand factor. Proc. Natl. Acad. Sci. USA. 82:6394-6398.

57. Yamada, K. M., and D. W. Kennedy. 1987. Peptide inhibitors of fibronectin, laminin, and other adhesion molecules: unique and shared features. J. Cell. Physiol. 130:21-28.

58. Ginsberg, M., M. D. Pierschbacher, E. Ruoslahti, G. Marguerie, and E. Plow. 1985. Inhibition of fibronectin binding to platelets by proteolytic fragments and synthetic peptides which support cell adhesion. J. Biol. Chem. 260:3931-3936. 